Smartphone, video games and other new technologies on hand joints in patients with psoriasis

Kluger, N.

2018-12

Kluger , N 2018 , ' Smartphone, video games and other new technologies on hand joints in patients with psoriasis ' , Journal of the European Academy of Dermatology and Venereology , vol. 32 , no. 12 , pp. E457-E457 . https://doi.org/10.1111/jdv.15053

http://hdl.handle.net/10138/307718

https://doi.org/10.1111/jdv.15053

publishedVersion

Downloaded from Helda, University of Helsinki institutional repository.

This is an electronic reprint of the original article.

This reprint may differ from the original in pagination and typographic detail.

Please cite the original version. 


\section{Smartphone, video games and other new technologies on hand joints in patients with psoriasis}

\section{Dear Editor,}

I read with great interest the article by Megna et al. regarding the potential effects of smartphone addiction on the hand joints of individuals and patients with psoriasis. ${ }^{1}$ The working hypothesis of the authors is appealing, but could fit in the broader scope of new technologies. Overuse syndrome is one of the known sideeffects of mobile phone and smartphone overuse, as well as video games joysticks and controllers. ${ }^{2,3}$ Besides, the keyboard style of patients with rheumatoid arthritis may have the potential to put stress on joints that are already affected by the disease. ${ }^{4}$ The generations born after 1977 (Xennials, Millenials...) have learnt to use mobile phones (text messaging using the dominant thumb), and smartphones (texting using either the dominant thumb or both thumbs), but also practice gaming with video game consoles or smartphones. Acknowledging that other non-related daily activities may have an effect on the hand joints, the impact of past or present intense video gaming on joints and tendons in (young) patients with psoriasis is most likely worth evaluating (Fig. 1).

N. Kluger* Department of Dermatology, Helsinki University Central Hospital and University of Helsinki, Helsinki, Finland *Correspondence: N. Kluger, E-mail: nicolas.kluger@hus.fi

Linked article: This article is commentary on by M. Megna et al., pp. e457-e458 in this issue. To view this article visit https://doi.org/10.1111/ jdv. 15056

\section{References}

1 Megna M, Gisonni P, Napolitano $\mathrm{M}$ et al. The effect of smartphone addiction on hand joints in psoriatic patients: an ultrasound-based study. J Eur Acad Dermatol Venereol 2018; 32: 73-78.

2 Kluger N, Pecquet C. Dermatoses associated with high technology (cell phones, computers and video games). Ann Dermatol Venereol 2012; 139: 230-238; quiz 229, 239.

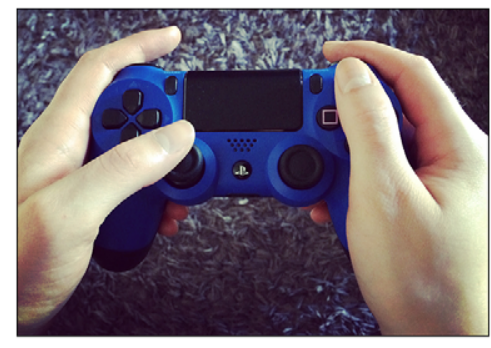

Figure 1 Should the impact of overuse of both thumbs during video gaming be assessed in patients with psoriasis?
3 Jalink MB, Heineman E, Pierie JP, ten Cate Hoedemaker HO. Nintendo related injuries and other problems: review. BMJ 2014; 349: g7267.

4 Baker NA, Gustafson NP, Rogers J. The association between rheumatoid arthritis related structural changes in hands and computer keyboard operation. J Occup Rehabil 2010; 20: 59-68.

DOI: $10.1111 / j d v .15053$

\section{Smartphone and video games overuse effects on hand joints: time for screening interventions?}

Dear Editor,

We read with great interest the letter by Kluger, ${ }^{1}$ and we completely agree that apart from smartphone addiction ${ }^{2}$ also other technologies overuse such as video games joysticks and controllers may have an effect on hand joints. Particularly, we have previously demonstrated that in psoriasis patients, smartphone overuse is linked with higher signs of inflammation of musculoskeletal structures of hands joints potentially being a factor which facilitate or speed up the possible development of psoriatic arthritis (PsA). ${ }^{2}$ This concept could be easily extended to other technologies which strain hand joints such as video games and tablets. Indeed, their overuse has already been linked to different harmful effects. ${ }^{3,4}$ Nowadays, a clear trend of rising of PsA incidence has been showed. ${ }^{5}$ Apart from increased attention by patients and physicians, other causes remain unclear. Technologies such as smartphone and video games, due to their widespread diffusion, may therefore constitute a possible contributing factor to PsA increased incidence. For all these reasons, early PsA screening interventions including specific questionnaires [e.g. Psoriasis Epidemiology Screening Tool (PEST), Toronto Psoriatic Arthritis Screening (ToPAS), the early psoriatic arthritis screening questionnaire (EARP)], clinical examination and/or ultrasound investigations should be performed especially in patients at high risk of smartphone and video games addiction such as teenagers and young adults, in order to precociously detect any alterations, preventing or limiting PsA development and/or joint damage. However, together with PsA screening interventions, information campaigns regarding potential harmful effects linked to smartphone and video games overuse are strictly needed to limit the diffusion of incorrect life styles, acting as primary prevention campaign.

M. Megna, ${ }^{1, \star}$ P. Gisonni, ${ }^{2}$ N. Balato ${ }^{1}$

${ }^{1}$ Department of Dermatology, University of Naples Federico II, Naples, Italy, ${ }^{2}$ Department of Advanced Biomedical Sciences, Diagnostic Imaging Section, University of Naples Federico II, Naples, Italy ${ }^{*}$ Correspondence: M. Megna. E-mail: mat24@libero.it 